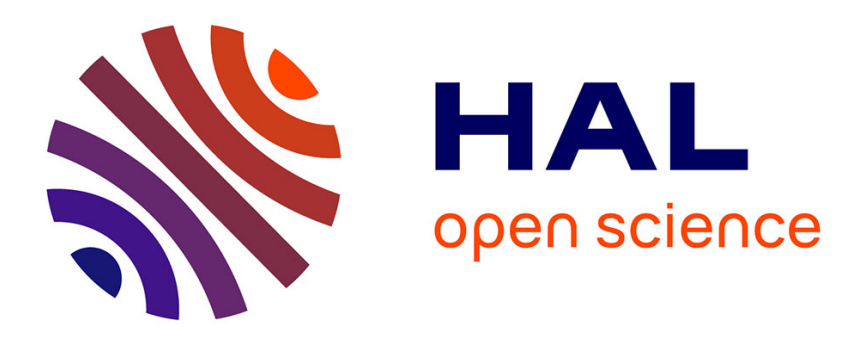

\title{
Energy extraction of diode pumped laser rods : a comparison Nd: LNA vs Nd: YAG
}

\author{
A. Jolly, J. Vicrey
}

\section{To cite this version:}

A. Jolly, J. Vicrey. Energy extraction of diode pumped laser rods: a comparison Nd: LNA vs Nd: YAG. Journal de Physique IV Proceedings, 1994, 04 (C4), pp.C4-365-C4-368. 10.1051/jp4:1994487 . jpa-00252750

\section{HAL Id: jpa-00252750 https://hal.science/jpa-00252750}

Submitted on 1 Jan 1994

HAL is a multi-disciplinary open access archive for the deposit and dissemination of scientific research documents, whether they are published or not. The documents may come from teaching and research institutions in France or abroad, or from public or private research centers.
L'archive ouverte pluridisciplinaire HAL, est destinée au dépôt et à la diffusion de documents scientifiques de niveau recherche, publiés ou non, émanant des établissements d'enseignement et de recherche français ou étrangers, des laboratoires publics ou privés. 


\title{
Energy extraction of diode pumped laser rods: a comparison Nd: LNA vs Nd: YAG
}

\author{
A. JOLLY and J. VICREY
}

CEA, Centre d'Etudes de Bruyères, BP. 12, 91680 Bruyères-le-Châtel, France

1. - Introduction. The $\mathrm{Nd}$ : LNA laser material, whose chemical formula is $\mathrm{Nd}_{(\mathrm{x})} \mathrm{La}_{(1-\mathrm{x})} \mathrm{MgAl}_{11} \mathrm{O}_{19}$ may be doped with a Neodymium proportion $x=15 \%$. It has a smoothly varied bandwith of absorption [1], which is a highly desirable feature for diode pumping. In this paper, we present new results devoted to large size rods in the long pulse and Qswitched modes of operation, and a computation of the crystal's effective stimulated emission cross section and quantum efficiency. Twenty GaAlAs stacks from Spectra Diode Labs., each made of four $795 \mathrm{~nm}$ laser bars and referenced as SDL $3230 \mathrm{TZC}$ parts, are closely coupled to $4 \mathrm{~mm}$ in diameter LNA rods. The overall peak pumping power is $4.8 \mathrm{Kwatts}$, within $400 \mu \mathrm{s}$ wide pulses.

2. - Laser experiments and calculations. The laser head is placed inside a plano concave resonator which is defined by a $3 \mathrm{~m}$ concave high reflector and a flat $70 \%$ reflecting output coupler, the length of the oscillator being $50 \mathrm{~cm}$. The very high order multimode beam completely fills the rod volume so as to extract as much of the available energy as possible. In a first step we analyse, with the help of a CCD camera, the spatial distribution of the induced fluorescence across the rod. The measurements are compared to the results of a Monte carlo computation [3]. The derivation of the diode deposited energy is made throughout the rod's whole cross section, on Fig. 1, and the optical losses are also computed over it's dark side. Our simulation takes into account a number of parameters, such as the linear absorption of the Nd:LNA at $795 \mathrm{~nm}\left(4.5 \mathrm{~cm}^{-1}\right)$, the rod diameter (4 mm) and diode-rod distance $(0.5 \mathrm{~mm}$ ), the intensity diagram ( 40 degrees divergence in the direction perpendicular to the diode junction plane) and mean near field emittance of the diodes, and the rod surface diffusion term. That way, best Monte carlo fits are obtained with $30 \%$ diffusion. The computed diades-rod coupling efficiency equals $81 \%$.
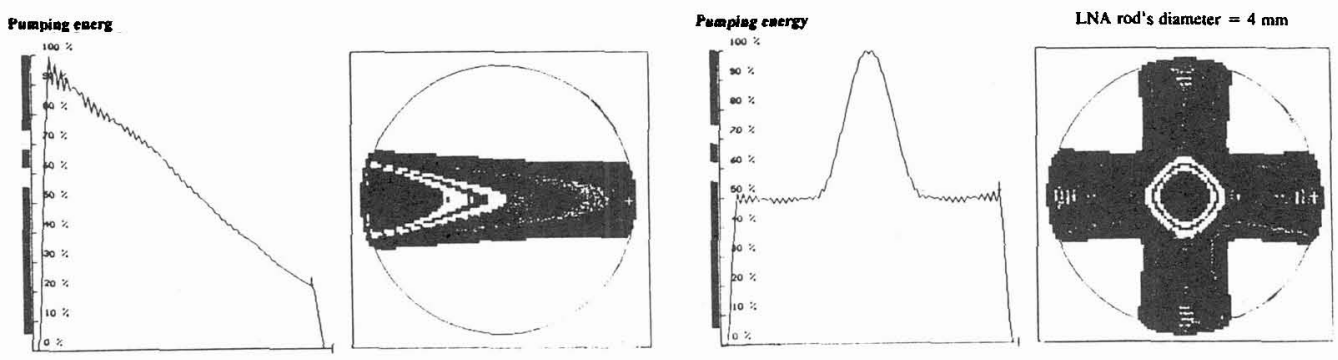

0.5

distance from dindes' facels

Fig.1. - Modelling the spatial distribution of the pumping energy inside the LNA rod, closely pumped by one diode plane: the best fit with fluorescence measurements is obtained with $30 \%$ Lambertian diffusion and $70 \%$ Fresnel refraction.

Then, we fire the complete laser head inside the above resonator. When free running at $25^{\circ} \mathrm{C}$ without any other intracavity optical component, the LNA rods generate 300 to $350 \mathrm{~mJ}$ within $400 \mu \mathrm{s}$ in the long pulse mode. The corresponding optical efficiency is 16 to $18 \%$. Fig. 2 illustrates the decrease of the output energy when a deuterated $\mathrm{KD} * \mathrm{P}$ cell is placed inside the resonator, before it is activated. The Pockels cell is made of a $\mathrm{KD} * \mathrm{P}$ crystal with plane-parallel faces and AR coated windows, and a Glan polarizer. The additional intracavity losses lead to an available output energy equal to $180-200 \mathrm{~mJ}$, i.e. the optical efficiency is reduced to about 10\%. Fig. 2 also illustrates the short pulse efficiency, the above Pockels cell being operated at the quarter wave voltage 3.4 Kvolts. Depending on the actual LNA rod and intracavity polarizer used, the energy within the output pulse is 100 to $145 \mathrm{~mJ}$, at a 20 to $40 \mathrm{~ns}$ fwhm width. The corresponding optical efficiency still equals 5.2 to $7.6 \%$. 
We experience a Findlay -Clay procedure [4] for the measurement of effective LNA's internal losses and small signal gain coefficient"go". Losses are determined by varying the output coupler reflectivity from 50 to $95 \%$, and measuring the corresponding pump threshold. The main errors in the least square - straight line based - derivation come from the uncertainties on the measurement of the diode current, even though we used a wide range and large number of output reflectivities. These errors may be estimated as $+/-15 \%$ and $+/-10 \%$ peak to peak, respectively for the losses $L$ and the gain. The rod's intrinsic losses and gain are $L$ \# $18 \%$ and Go \# 2.76 for 1.9 Joule diode pumping. This means the gain coefficient go of the LNA equals $0.29 \mathrm{~cm}^{-1}$ at 1 Joule diode pumping, by comparison with $0.455 \mathrm{~cm}^{-1}$ for YAG [5]. The insertion of the Pockels cell inside the resonator lead to 10 $14 \%$ additional losses.

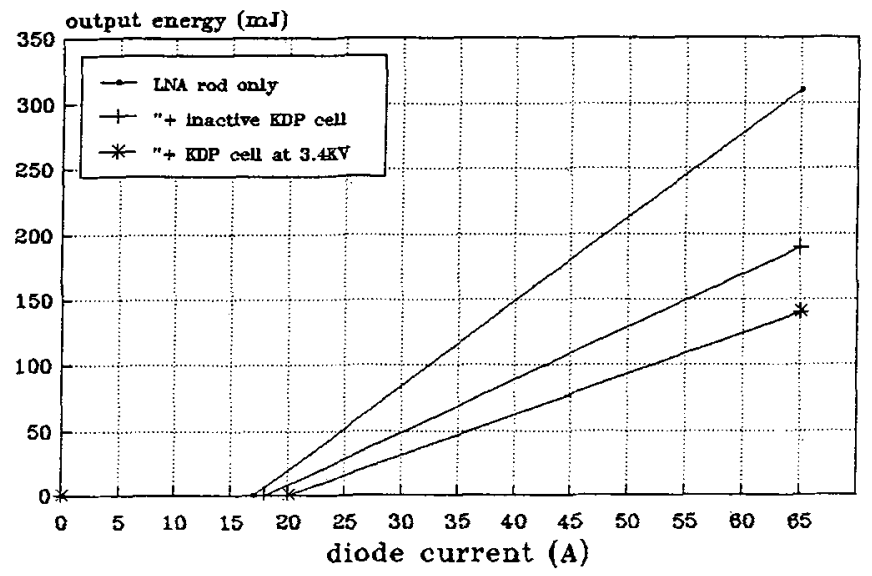

Fig.2. - LNA extracted energy vs optical configuration. long pulse and Qswitched modes of operation with different intracavity optical components are investigated.

Table 1 below depicts the useful parts in the overall efficiency and energy-transfert mechanisms inside the oscillator. The Qswitch extraction efficiency $\eta_{\mathrm{E}}$ is derived at the optimum output reflectivity $70 \%$ with the help of Zayhowski's method [6]. The coefficient $z$, when defined as $z=2 * g_{0} * l_{0} / L$, is about 14 , which leads to an extraction efficiency $\eta_{e q} \# 75 \%$. In the former $z$ expression, $l_{0}$ and $L$ represent the active rod length and FindlayClay losses. Accordingly, we find that the LNA's quantum efficiency $\eta_{\mathrm{q}}$ is half that of the YAG, which is about 95\%[5]. For our actual LNA rods :

$$
\eta_{\mathrm{q}}=\left(\mathrm{E}_{\mathrm{out}} / \mathrm{E}_{\mathrm{pump}}\right) /\left(\eta_{\mathrm{T} .} \eta_{\mathrm{a} .} \eta_{\mathrm{B} .} \eta_{\mathrm{S} .} \eta_{\mathrm{St} .} \eta_{\mathrm{ASE} .} \eta_{\mathrm{EQ}}\right) \# 45 \%
$$

\begin{tabular}{|c|c|c|c|}
\hline Notations & Energy transfert process & Estimated efficiency (\%) & Criteria / assumptions \\
\hline$\eta_{\mathbf{T}}$ & coupling geometry and diffusion & $\# 80$ & $\begin{array}{l}\text { Fresnel losses only, due to the } \\
\text { uncoated rod surface }\end{array}$ \\
\hline$D_{0}$ & Spectral absorption & 80 & LNA peak absorption \\
\hline$\eta_{\mathbf{R}}$ & $\begin{array}{l}\text { beam overlap with the pumped } \\
\text { volume }\end{array}$ & 100 & \begin{tabular}{|l|l|l}
$\begin{array}{l}\text { fully multimode energy } \\
\text { extraction }\end{array}$ \\
\end{tabular} \\
\hline$\eta_{\mathrm{S}}$ & Stockes' shif & 75.5 & \\
\hline$\eta_{\text {ASF }}$ & $\begin{array}{l}\text { reciprocal of the depopulation } \\
\text { rate of the upper level, due to } \\
\text { fluorescence }\end{array}$ & 100 & $\begin{array}{l}\text { no amplified stimulated } \\
\text { emission, with AR coated faces } \\
\text { and moderated gain }\end{array}$ \\
\hline$\eta_{\mathrm{st}}$ & $\begin{array}{l}\text { storage efficiency in the upper } \\
\text { level }\end{array}$ & 52 & $\begin{array}{l}\text { pumping duration and } \\
\text { fluorescence decay times } \\
\# 400 \mu \mathrm{s} \text { and } 280 \mu \mathrm{s} \\
\end{array}$ \\
\hline$\eta_{\text {en }}$ & $\begin{array}{l}\text { Qswitch energy extraction from } \\
\text { the upper level }\end{array}$ & 75 & $\begin{array}{l}\text { cf. Zayhowski [6], with best } \\
\text { output coupling } \# 80 \%\end{array}$ \\
\hline
\end{tabular}

Table 1. Energy conversion processes, estimated numerical values and associated computation procedures. 
In a second step, we develop a Runge-Kutta computation to determine the effective stimulated emission cross section $\sigma$. The modelization of the Qswitched laser operation is made with the help of a 4 level scheme, including the effects of a low but finite lower level lifetime $\tau 10$ : accounting for $\tau_{10}$ is of a prime importance with respect to the accuracy of the computed pulse shapes and energies [7]. But the value of $\tau_{10}$ in the case of LNA is not a well known value. As a result, we have to make the simulations within a broad range of values, namely from 1 to 100 ns.

$\begin{array}{|lll|}\mathrm{dN}_{2} / \mathrm{dt} & =-\sigma / \mathrm{h} v \cdot \mathrm{I} \cdot \varphi_{\mathrm{S}} \cdot\left(\mathrm{N}_{2}-\mathrm{N}_{1}\right) \\ \mathrm{dN}_{1} / \mathrm{dt} & =+\sigma / \mathrm{h} v \cdot \mathrm{I} \cdot \varphi_{\mathrm{S}} \cdot\left(\mathrm{N}_{2}-\mathrm{N}_{1}\right)-\mathrm{N} 1 / \tau_{10} \\ \mathrm{~d}\left(\mathrm{I}^{*} \varphi_{\mathrm{S}}\right) / \mathrm{dt} & =+\sigma / \mathrm{h} v \cdot \mathrm{I} \cdot \varphi_{\mathrm{S}} \cdot\left(\mathrm{N}_{2}-\mathrm{N}_{1}\right)-\mathrm{I} / \tau_{\mathrm{c}}(4) \\ \mathrm{N}_{0} & =1-\mathrm{N}_{1}-\mathrm{N}_{2}\end{array}$

Table2. - Simplified rate equations of the LNA. $\mathrm{N}_{1}, \mathrm{~N}_{2}, \mathrm{~N}_{0}$ are the lower level, metastable and fundamental populations. I, h $v$ and $\tau_{c}$ are the associated photon density, photon energy and cavity lifetime. $\sigma / h v . I$. $\left(\mathrm{N}_{2}-\mathrm{N}_{1}\right)$ is the stimulated emission part, $-\mathrm{N} 1 / \tau_{10}$ and $-\mathrm{I} / \tau \mathrm{c}$ are the relaxation parts. $\varphi \mathrm{S}$ is a reference power level, expressed in Gwatts $/ \mathrm{cm}^{2}$.

Fig.3-a illustrates the dependancy of the pulse shape $P(t)$ with $\sigma$, for a number of values ranging from 3 to $1510^{-20} \mathrm{~cm}^{2}$. We calculate that $\sigma$ must equal $610-20 \mathrm{~cm}^{2}$, in order to extract an output energy Eout $=1.3 \mathrm{~J} / \mathrm{cm}^{2}$ within 40 ns. The peak power is $P_{\text {peak }}=0.2$ Gwatts $/ \mathrm{cm}^{2}$. We examine on Fig.3-b the effects of 710 : increasing $\tau 10$ from 1 to 10 ns only leads to tiny $P_{\text {peak }}$ and Eout variations, while increasing $\tau 10$ within the 15-100 ns range of values leads to a dramatic increase of $P_{\text {peak }}$, at nearly the same pulse width.
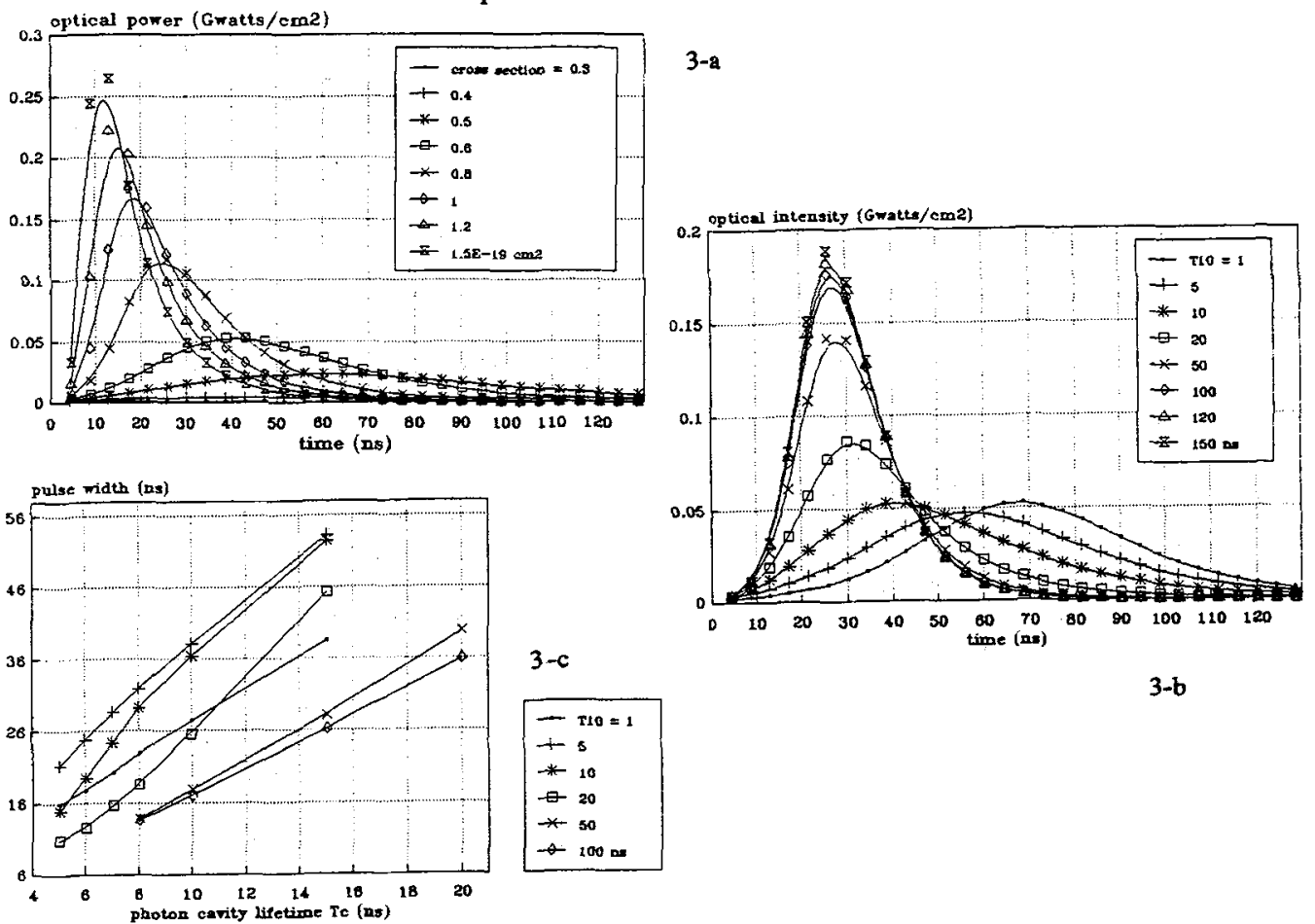

3-b

Fig.3.- Computation of the Qswitched pulse versus LNA laser parameters. The cavity length is $45 \mathrm{~cm}$ and the photon lifetime in the upper plots $-a$ and $-b$, is $\tau_{c}=7 n s$.

When we go on increasing $\tau_{10}$, for example from $100 \mathrm{~ns}$ to $1 \mu \mathrm{s}$, a weaker dependancy of $E_{\text {out }}$ and $P_{\text {peak }}$ is observed, and pulses tend to superimpose. We believe this occurs because $N_{1} / 110$ becomes negligible with respect to the other terms, in (2)-(5). Referring to otherwise published YAG's data [5], the value of $\tau 10$ for LNA is supposed to stand below 15 ns. So, the uncertainties on latter fits can be estimated at $+/-10 \%$. Fig.6-c illustrates the variation of the pulsewidth within the range $E_{\text {out }}=100$ to $150 \mathrm{~mJ}$, for $\tau 10=1$ to $15 \mathrm{~ns}$ and cavity lifetimes $\tau_{\mathrm{c}}=5$ to $20 \mathrm{~ns}$. Best fits of the simulations with experiments provide $\sigma \# 0.610^{-19} \mathrm{~cm} 2$, at $\tau 10=5$ to $15 \mathrm{~ns}$. 
3. - Room temperature effects. At the opposite of the usual Nd:YAG crystal, and because of strong inhomogeneous broadening effects, the LNA exhibits a fairly flat absorption band between 792 and $806 \mathrm{~nm}$. The YAG requires the diode temperature to be precisely adjusted so that the pumping wavelength is kept nearby $808 \mathrm{~nm}$ as closely as possible, and consequently, so that the output energy remains unchanged. The absorption spectrum of $5 \mathrm{~mm}$ thick LNA sample is plotted in Fig.4, together with the temperature behaviour of the above oscillator.

The temperature dependant output energy of our diode pumped oscillator is not only limited by the spectral coupling efficiency. It also depends on the variation of the crystal's intrinsic laser parameters, the induced optical effects, and on the shift of the diode current threshold with temperature. When pumped with $250 \mu \mathrm{s}$ wide pulses, the YAG output roughly varies from 60 to $200 \mathrm{~mJ}$ with temperatures ranging between 5 and $65^{\circ} \mathrm{C}$, while the LNA output varies from 130 to $150 \mathrm{~mJ}$ for $400 \mu$ s wide pumping pulses. The YAG's $220 \mathrm{~mJ}$ output is related to the highest pumping wavelength we could obtain for diode stacks' reasonable operating conditions, and is only $2 \mathrm{~nm}$ below the $808 \mathrm{~nm}$ peak absorption of the crystal. After the thermal shift of the diodes has been subtracted, the comparison of these $220 \mathrm{~mJ}$ with the LNA's $150 \mathrm{~mJ}$ output provides a good estimate of the discrepancy between peak efficiencies: about $8 \%$ with LNA, to be compared with nearly $13 \%$ with YAG.
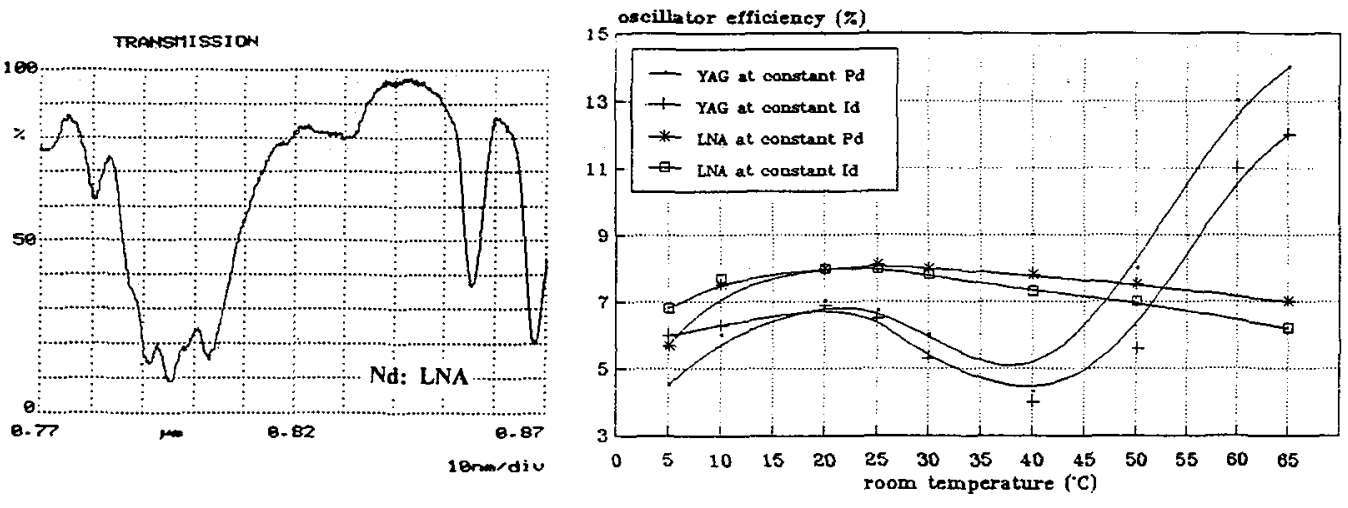

$P d=$ diode peak power

Id $x$ dinde current

Fig.4. - Nd: LNA absorption spectrum and compared thermal behaviour of the Qswitched LNA and YAG oscillators.

4. - Conchusion. The implications of the differing features of Nd:YAG versus LNA may be discussed in terms of wall-plug efficiency and volume. The Nd:LNA material is a good candidate for high energy at high efficiency, compact lasers. Despite its somewhat reduced stimulated emission cross section, whose effective value $0.610-19$ $\mathrm{cm}^{2}$ is by a factor 4 lower than that of the YAG, the LNA material can produce Qswitched pulses in the 100 to 200 $\mathrm{mJ}$ range. We performed an $7.6 \%$ optical Qswitch efficiency in the actual multimode configuration. This efficiency is limited by the intrinsic losses of additional intracavity components. There is no need of any temperature control within a 5 to $65^{\circ} \mathrm{C}$ range of temperatures, and the material has a fairly good energy storage capability. This allows the number of stacks to be minimized, which provides a compact and temperature insensitive laser source.

5. - Acknowledgements. We would like to thank the CEA's team P. Cottin, A. Dechatre, A. Burkhart and W. D' Hespel for the promotion of the project and the numerous useful discussions we had, and our colleagues from the LETI/ Grenoble, C. Wyon and J.J. Aubert, and G. Girard from LASERDOT for their contribution.

6. - References. [1]
CEA/LETI/DOPT- and associated labs. report "BRTTE contract: RI 1B -0245$C^{\prime \prime}$, project $\quad \mathrm{n}^{\circ} \mathrm{P} .2112 / 2-87$-report $2 / 6,11 / 12 / 89$

Spectra Diode Labs. technical data and product catalog $n^{\circ}$ DCC 001 EK 0492, 1992

OPTIS company, technical documentation, Solstis optical software. CEA/DAM 1992 specific developments.

D. Findlay and R.A. Clay "The measurement of internal losses in 4 level lasers", Phys. Letters Vol.20 n $3,15 / 02 / 66$, p. 277

W. Koechner, "Solid state laser engineering", $3^{\text {rd }}$ Ed. 1992, Springer Verlag J.J. Zayhowski and P.L. Kelley "Optimisation of Qswitched lasers", IEEE J. of Quantum Electronics, Vol.27, n9, Sept. 1991, p. 2220

T.Y. Fan "Effect of finite lower level lifetime on Qswitched lasers", IEEE J. of Quantum Electronics, Vol.24, n ${ }^{\circ} 12$, Dec. 1988, p. 2345 